\title{
Can biosimilars help achieve the goals of US health care reform?
}

This article was published in the following Dove Press journal:

Cancer Management and Research

I June 2017

Number of times this article has been viewed

\author{
Ralph Boccia' \\ Ira Jacobs ${ }^{2}$ \\ Robert Popovian ${ }^{3}$ \\ Gilberto de Lima Lopes J $r^{4}$ \\ 'Center for Cancers and Blood \\ Disorders, Bethesda, MD, ${ }^{2}$ Global \\ Medical Affairs, Pfizer Inc., New York, \\ NY, ${ }^{3}$ US Government Relations, Pfizer \\ Inc., Washington, DC, ${ }^{4}$ Sylvester \\ Comprehensive Cancer Center, \\ University of Miami, Miami, FL, USA
}

\begin{abstract}
The US Patient Protection and Affordable Care Act (ACA) aims to expand health care coverage, contain costs, and improve health care quality. Accessibility and affordability of innovative biopharmaceuticals are important to the success of the ACA. As it is substantially more difficult to manufacture them compared with small-molecule drugs, many of which have generic alternatives, biologics may increase drug costs. However, biologics offer demonstrated improvements in patient care that can reduce expensive interventions, thus lowering net health care costs. Biosimilars, which are highly similar to their reference biologics, cost less than the originators, potentially increasing access through reduced prescription drug costs while providing equivalent therapeutic results. This review evaluates 1) the progress made toward enacting health care reform since the passage of the ACA and 2) the role of biosimilars, including the potential impact of expanded biosimilar use on access, health care costs, patient management, and outcomes. Barriers to biosimilar adoption in the USA are noted, including low awareness and financial disincentives relating to reimbursement. The evaluated evidence suggests that the ACA has partly achieved some of its aims; however, the opportunity remains to transform health care to fully achieve reform. Although the future is uncertain, increased use of biosimilars in the US health care system could help achieve expanded access, control costs, and improve the quality of care.
\end{abstract}

Keywords: Affordable Care Act, biologics, health policy, patient care, access

\section{Introduction to health care reform in the USA}

The Patient Protection and Affordable Care Act (ACA), which became a law in the USA on March 23, 2010, ${ }^{1}$ aims to solve long-standing challenges the US health care system is facing related to access, affordability, and quality of care. ${ }^{2}$ Although the ACA is under scrutiny from the current US administration, its aims to expand coverage, contain costs (despite additional coverage-based use), and improve health care quality ${ }^{3}$ are likely to continue under a revised health care act, even if repealed and replaced. The ACA, as it stands, is intended to make health care more affordable for families, seniors, businesses, and taxpayers alike and to facilitate coverage of previously uninsured Americans, as well as those whose insurance coverage is still inadequate. ${ }^{4}$ Addressing access to and affordability of innovative biopharmaceuticals is an important part of the ACA. Of particular interest is the role of biosimilars in improving access and patient care.

Biosimilars are medicinal products demonstrated to be highly similar to an alreadyapproved biological product. ${ }^{5,6}$ Unlike generics of small molecules, which are relatively easy to produce and do not require clinical trials for regulatory approval, biologics cannot be duplicated because of the complexity in the manufacturing process. In addition,
Correspondence: Ira Jacobs

Global Medical Affairs, Pfizer Inc., 235 East 42nd Street, New York, NY 10017-5755, USA

Tel + I 2127330876

Fax + I 845474530 I

Email ira.jacobs@pfizer.com 
unlike generics, clinical trials are required for biosimilars to demonstrate product biosimilarity. The ACA amended the Public Health Service Act to create a tailored licensure pathway for biological products that are demonstrated to be "biosimilar" to or "interchangeable" with a biological product already licensed by the US Food and Drug Administration (FDA). This pathway has been defined in the Biologics Price Competition and Innovation Act (2009) $)^{5}$ and has opened the door to increased therapeutic options in the armorarium of patient care.

Following the first approval of biosimilar filgrastim in the USA in June 2015 (used in oncology as supportive care), as of 2016, the FDA approved biosimilar versions of immunotherapies infliximab, etanercept, and adalimumab. ${ }^{7}$ In Europe, biosimilar filgrastim and biosimilar infliximab have been available since 2008 and 2013, respectively. ${ }^{8}$ Despite the inclusion of a tailored licensure pathway for biosimilars in the US health care reform legislation, the introduction and uptake of biosimilar products in the USA have been slow, mainly due to a lack of statutory guidance, ${ }^{9}$ higher hurdles to entry compared with generic products, ${ }^{10}$ and a general lack of familiarity with biosimilar products. Recent FDA guidance regarding nonproprietary naming of biologic products has provided some clarity. Each biosimilar is assigned a core name consistent across the originator biologic, any related biologic products, and biosimilars, with a suffix of four lower-case letters unique to each biosimilar or related biologic product of the originator biosimilar. ${ }^{11}$ Important unanswered questions remain, notably around the issue of interchangeability and the extent to which patients treated with a biologic might be switched to a biosimilar, or whether biosimilar uptake will primarily be in treatment-naïve patients. ${ }^{12}$

The objective of this review was to evaluate the progress made toward achieving health care reform since the passage of the ACA, the role of biosimilars in facilitating the aims of the ACA in terms of containing health care costs and improving disease management and outcomes, and possible barriers to biosimilar uptake, including a lack of awareness and financial disincentives relating to reimbursement.

\section{Achievements of the ACA since enactment}

Following the introduction of the ACA, $\sim 20$ million additional Americans gained health insurance. ${ }^{2,3,13,14}$ The ACArelated reforms, including transformed health care payment systems, contributed to a sustained period of slow growth in per-enrollee health care spending. ${ }^{2}$ Cost reductions were particularly evident for Medicare and Medicaid, ${ }^{13}$ and Medicare spending per beneficiary declined on an inflation-adjusted basis through $2014 .^{3}$

In addition to saving costs, the ACA has improved the quality of health care delivery, as evidenced by improved health outcomes. For example, an estimated reduction of $3.4 \%$ in the share of nonelderly adults with fair or poor health has been reported. ${ }^{2}$ The ACA has also led to the formation of Accountable Care Organizations (ACOs). ACOs comprise physicians, hospitals, and other providers who aim to deliver cost-effective, coordinated care to Medicare beneficiaries and to take responsibility for overall provision, cost, and quality of patient care. ${ }^{15}$ It has been estimated that 23.5 million Americans are now served by an ACO. Some ACOs have resulted in improvements in health service quality measures, including clinician communication, timely access to physicians, and overall patient satisfaction. ${ }^{14}$

Despite these advances, a full accounting of the ACA to date has yet to be undertaken, and there remain major opportunities for US health care reform and health care improvement. ${ }^{2}$ For example, there is a lack of comprehensive, robust data on health outcomes before and after the ACA. ${ }^{3,13}$ Although more people have health insurance post-ACA, the level of individual coverage is still low. Many enrollees select bronze-level insurance plans, which essentially provide only catastrophic coverage. ${ }^{16}$ Adequate coverage is still unaffordable to many, and out-of-pocket costs have increased. Medicaid and Medicare Advantage coverage has expanded, and employer-sponsored plans have remained at the expense of state-sponsored exchange plans. ${ }^{3,16}$ Some insurance companies (eg, Dartmouth ${ }^{17}$ and UnitedHealthcare ${ }^{18}$ ) are dropping out of "ObamaCare" exchanges, as these are viewed as financially unattractive, and key stakeholders are withdrawing from the ACO market. Expanded health insurance coverage of high-risk patients and pressure to reimburse expensive cancer treatments and immunotherapy-based therapies have resulted in costs that have not been offset by enrollment of less expensive younger healthier patients, which has been low. ${ }^{14}$ In order to manage costs, health plans may consolidate, which would reduce competition and potentially drive up prices for consumers. Health care providers must address these and future challenges, such as rising costs, to ensure the continued success of the ACA.

\section{Potential role of biosimilars in supporting US health care reform}

\section{Health care cost reduction}

Controlling drug expenditure will be key to preventing future health care cost inflation and ensuring the viability of the 
ACA. The former US President, Barack Obama, highlighted lowering prescription drug costs as an area for improvement. ${ }^{2}$ Specialty medicine is one of the fastest growing areas, expected to expand considerably in the next 10 years, as new biologics and high-cost therapies become available. Biologics, most of which are in the specialty medicine category, are often more expensive and it is substantially more difficult to manufacture them compared with small-molecule drugs, many of which have generic options. Although biologics increase drug costs, they have demonstrated significant improvements in patient care that can avoid more expensive interventions such as hospitalizations. More information about the overall budget impact and cost-effectiveness of biologics is required.

Biosimilars, highly similar to biologics, are less expensive than the originators (discounts vary by market and product), ${ }^{19,20}$ offering the potential to reduce prescription drug costs while providing equivalent care. The Centers for Medicare and Medicaid Services (CMS) noted that biosimilars may provide an option for Part D (prescription drug benefit) sponsors to control costs while ensuring access to needed medication. ${ }^{21}$ The Rand Corporation ${ }^{22}$ reported that the use of biosimilars is estimated to result in US health care system cost savings of $\$ 44.2$ billion (range, $\$ 13-\$ 66$ billion) between 2014 and 2024 ( $4 \%$ of total biologic spending), from reductions in direct spending on biologics.

The introduction of competition from biosimilars may also create a downward pressure on biologic drug prices. In Europe (Scandinavia, in particular ${ }^{12}$ ), competition among biosimilars has resulted in discounts of up to $69 \%$ on the price of some originator biologics. ${ }^{23-25}$ In Japan, discounts are up to $67 \%$, and in South Korea, although the biologics market as a whole is growing, originator biologics are rapidly losing market share. ${ }^{25}$ In Europe, biosimilars (available since 2006) of many biologics are priced between $10 \%$ and $30 \%$ lower than the originator. ${ }^{26}$ These discounts, however, are not in place in all markets or among all types of biosimilars, such as the newer monoclonal antibody and fusion protein biosimilars. ${ }^{12,27}$

Reductions in health care costs to payers arising from biosimilar availability as an alternative to the originator biologic will have maximum benefit to multiple stakeholders if translated into lower premiums and reduced out-of-pocket costs for patients, which could increase patient access to biologics (originators and biosimilars). For example, previously uninsured young adults with inflammatory bowel disease, a condition most effectively managed by biologics, ${ }^{28}$ may now have better access to these agents through health care coverage under the ACA. A clinical practice study from Italy's Lazio region found increased use of filgrastim biosimilar after its introduction, resulting in estimated annual granulocyte-colony stimulating factor expenditure reduction of $\sim 5 \% .{ }^{29}$ Furthermore, a simulation of cost savings in major European countries found that the use of biosimilar filgrastim could result in not only potential cost savings, but also budget availability for greater access to important cancer therapies such as rituximab and trastuzumab. ${ }^{30}$

One large US pharmacy benefits manager has taken advantage of lower pricing and replaced filgrastim with its biosimilar in its formulary management strategy. ${ }^{31}$ If biosimilars are increasingly used in place of originator biologics when the originators are more expensive, then cost savings may be analogous (albeit perhaps not as substantial) to those seen with generic substitution of small-molecule drugs. For example, after closure of the Medicare Part D coverage gap (the "donut hole"), patients' out-of-pocket spending significantly decreased among Medicare beneficiaries, mainly due to reduced spending on brand-name drugs and increased generic drug utilization. ${ }^{32}$ It remains to be seen how biosimilar availability will affect pricing and drug utilization covered under Medicare Part B. For example, the payment allowance limits of US CMS Part B drug (based on average sales price methodology) for the second quarter of 2017 were lower for filgrastim biosimilar, but higher for infliximab biosimilar than for their respective originators. ${ }^{33}$

\section{Expanding access to treatment and ensuring quality}

The FDA-approved biosimilar products have demonstrated similar efficacy and safety to their originator biologics in clinical trials. ${ }^{6}$ Health care decision-making to prescribe or reimburse biosimilars over originator biologics can reduce health care costs while maintaining quality and health outcomes. Where priced lower, biosimilars may expand access to appropriate treatment for conditions managed with biologics, allowing more patients to be treated, to be treated earlier, and to be treated with an expanded range of therapeutic interventions where previously restricted due to budget constraints. ${ }^{12,30}$ In March 2015, CMS indicated that with biosimilars, Medicaid programs could achieve cost savings and greater access to expensive therapeutic treatments for chronic conditions. ${ }^{21,34}$

Earlier access to treatment with biologics or approved biosimilars can lead to improved outcomes through symptom control and reduced symptom severity. For example, a study of patients with rheumatoid arthritis found that earlier 
treatment with biologics resulted in less joint damage and associated morbidity and longer maintenance of independence and productivity, compared with delayed treatment. ${ }^{35}$ Evidence of wider and earlier use of biologics (including biosimilars) is available in Europe, where biosimilars have been successfully adopted. ${ }^{29,30}$ Although the impact of increased access to biologics has not been assessed, increased use suggests a clinical need and the potential for improved patient outcomes. ${ }^{12}$ Given that certain subgroups have been shown to have poor adherence to biologic treatments due to high drug costs, ${ }^{36}$ observed improvements in outcomes may be enhanced by better adherence generated by the lower cost of biosimilars.

In addition to improvements in outcomes and adherence, health care quality can also be viewed in terms of the supporting services traditionally provided by the manufacturers of originator biologics. Manufacturers of approved biosimilars may offer similar services, such as specialist pharmacy services, patient-access support mechanisms, assistance with reimbursement administration, and assurance of continuous supply of product. ${ }^{37}$

\section{Importance of value}

The aim of the ACA to contain health care costs while improving quality and outcomes is in line with a more general shift in health care priorities from volume to value. Through health care cost reductions, expanded access to care, and ensuring quality, biosimilars add value to health care reform efforts already underway, such as the CMS Bundled Payments for Care Improvement (BPCI) initiative. The BPCI was launched in 2013 to assess whether episode-of-care-based payments could reduce costs to Medicare without adversely impacting quality. ${ }^{38}$ In a BPCI case study (which did not include biosimilars), bundled Medicare payments for lower-extremity joint replacement per episode decreased - primarily due to the reduced use of institutional post-acute care - without a significant change in quality outcomes. ${ }^{38}$

ACOs have been leading the way in ACA efforts to increase the value of health care. One component of this shift is the convergence of payer and provider concerns. Traditionally, payers have focused on costs such as direct pharmacy expenditures, whereas providers have been concerned with clinical outcomes. As health care reform transforms the health care landscape, payers and providers are increasingly being forced to grapple with the same concerns. In the vanguard of health care reform, ACOs are the advance scouts of the shift to value-based medicine. They are the first group of providers to grapple with cost-effectiveness, quality metrics, and patient satisfaction, and their innovations pave the way for more mainstream efforts.

\section{Barriers to biosimilar adoption in the USA}

While offering the potential to aid health care reform, considerable uncertainty remains about how biosimilars will fare under health care reform, as it is not entirely clear how important factors such as cost, clinical and real-world evidence, and policy will influence health care delivery and ongoing implementation of the ACA. ${ }^{39}$

\section{Perceptions of biosimilars}

Several opinion surveys of US health care professionals have highlighted a cautious reception of biosimilars, mainly driven by safety concerns and the need for more evidence. ${ }^{40-44}$ These surveys have emphasized that rigorous regulatory standards are needed for clinicians to consider biosimilars as acceptable alternatives to the standard of care. ${ }^{42}$ For example, most survey respondents wanted biosimilars to be identifiable as such and to have a different nonproprietary name from the innovator biologic medicine. ${ }^{42}$ Respondents also wanted any notable differences to be distinguished ${ }^{42}$ and felt that the originator's indications should not automatically be transferred to biosimilars. ${ }^{43,45}$ The transferability concern was especially resonant when it came to immunotherapies, in which one drug can have multiple indications for diverse diseases.

As noted in an industry-sponsored Biosimilars Forum Survey of 1,201 providers prescribing biologics across multiple therapeutic areas, prevalent perceptions may lead to a reluctance by some US physicians and payers to switch patients well maintained on biologics to biosimilars, especially for those requiring long-term treatment for chronic conditions such as rheumatologic and immunologic disorders. ${ }^{45}$ Health care professionals familiar with biologics, particularly rheumatologists and dermatologists, noted that long-term clinical evidence of the safety and immunogenicity of biosimilars was required for decision-making about their use in chronic disorders. ${ }^{45}$ The authors suggested that counterdetailing by certain manufacturers, which aimed at rheumatology practices to raise questions about the biosimilar pathway and the concept of biosimilarity, may have been a factor in the perceptions identified in the survey. ${ }^{45}$ Consequently, biosimilar uptake may be faster for acute diseases than for chronic diseases. Overall, surveyed US clinicians acknowledged the potential for biosimilars to increase patient access to a broader range of appropriate treatments and to reduce health care costs, ${ }^{45}$ with many 
receptive to prescribing, administering, or dispensing biosimilars; however, there remain substantial knowledge gaps and a need for information. ${ }^{41}$

\section{Financial disincentives to biosimilar adoption}

In some therapeutic areas, such as oncology, there is a financial incentive for both physician practices and institutions to use more expensive originator biologics rather than biosimilar drugs, as the markup, and thus profitability to the provider, is higher. According to a Memorial Sloan Kettering Cancer Center report, ${ }^{46}$ the markup of an infused medicine is greater in an inpatient setting than in a physician office, providing an incentive for institutions able to administer drugs in a setting that qualifies as inpatient. According to Jain et al, ${ }^{46}$ hospitals, in particular those participating in the 340B Drug Pricing Program, ${ }^{47}$ are most likely to profit from expensive medicines because the $49 \%$ collective profit associated with drug administration covered under Medicare Part B for drugs is unevenly allocated across doctors and hospitals. The blended profit margin translates into $\sim 16 \%$ for doctors, $140 \%$ for all hospitals, and $210 \%$ for $340 \mathrm{~B}$ hospitals; the difference is mainly due to commercial insurance contracts and steep discounts. In taking advantage of these profits, medication administration has shifted from physician offices to hospitals, accompanied by acquisitions and consolidation. ${ }^{48}$ These provision and reimbursement practices may result in disincentives to biosimilar uptake in these settings, although CMS has recently tried to neutralize this differential billing activity through a congressionally mandated policy on site-neutral payments for ambulatory care. ${ }^{49}$

Peculiarities in Medicare Part D reimbursement policy may result in biosimilars with acquisition costs lower than that of their original biologics having higher, rather than lower, out-of-pocket costs for patients. ${ }^{50,51}$ This occurs because manufacturers of branded products are expected to offer a discount for the coverage gap (donut hole), which does not apply to nonbranded products. In the coverage gap, enrollees currently pay $45 \%$ of the discounted price for branded drugs; their responsibility declines to $25 \%$ in 2020 . Currently, launched biosimilars (eg, filgrastim and infliximab) are addressed under Part B (medical benefit); thus, patient costs are not affected by the coverage gap. However, when monoclonal antibody biosimilars (eg, recently approved etanercept and adalimumab) reach the US market, they will be covered under Part D, ${ }^{51}$ which may result in a disincentive to biosimilar uptake.

\section{Uncertainty over cost savings with biosimilars}

The uptake of biosimilars in the USA may be hindered by uncertainties regarding the potential savings they offer and possibly by counterdetailing from companies manufacturing originator biologics. ${ }^{45}$ The authors of the Milliman study ${ }^{52}$ predict that if an employer with 10,000 insured employees and dependents spends on average $\$ 51.4$ million on health care, the expected cost for biologics would be $\$ 2.67$ million, or $5.2 \%$ of their total spend, the maximum savings potential if biosimilars were available at no cost. A 30\% discount for biosimilars would represent $\sim \$ 800,000$ savings, or $1.6 \%$; however, over time, the introduction of new biologics may work against the savings accompanying biosimilars. If financial incentives to use biologics and biosimilars lead to overuse, aggregate costs could go up despite lower unit drug costs, particularly where disease management is effective using lower-cost medications. This possibility creates additional uncertainties around cost savings from biosimilars.

\section{Overcoming barriers to biosimilar adoption and health care reform Changing perceptions of biosimilars in the USA}

The speed of regulatory approval may be a factor in biosimilar penetration into the US market. ${ }^{53}$ Litigation by originator manufacturers in the USA may also delay entry. As an increasing number of biosimilars overcome these hurdles, the readiness of US stakeholders to accept biosimilars will be determined in part by the availability of additional evidence about their safety and effectiveness. As the body of evidence needed for the FDA approval of biosimilars is at the molecular level rather than at the clinical level, there is some concern that there is less clinical evidence from randomized controlled trials than for the originator biologic. Therefore, studies on postapproval safety and real-world comparative effectiveness will be particularly important to instill confidence and demonstrate the value of biosimilars. Real-world administrative data that differentiate and track biosimilar use as well as costs can be used to measure the impact of wider access to biologic and biosimilar treatments, the potential evolution of the treatment algorithm, and the overall costs to the patient and the payer. However, real-world data collection is not without challenges, such as cost, time, and potential for bias.

As biosimilar infliximab has been available in Europe for several years for the treatment of Crohn's disease, gastroenterologists in Europe are more knowledgeable about and experienced in using biosimilars. It is uncertain whether this broad adoption of biosimilars in Europe will be 
echoed in the USA. ${ }^{54}$ A US survey of specialty physicians prescribing biologics conducted between November 2015 and January 2016 found a general lack of understanding and pressing need for education about biosimilars, particularly about the FDA approval process; the definition, safety, and efficacy of biologics versus biosimilars; and regulatory guidance for indication extrapolation, interchangeability, and pharmacy-level substitution. ${ }^{45}$ The generic market serves as an example of how practice changes as clinicians become more familiar with these alternate products (in particular, the uptake of generics such as warfarin and thyroid medication). ${ }^{55-57}$ Biosimilar uptake ultimately depends upon education - increased understanding about biosimilar production, regulation, and mechanism of action as well as experience in clinical practice.

\section{Financial incentives to biosimilar uptake in the USA}

Financial incentives for using less expensive treatments are now available in some US health care settings. With new value-based reimbursement demonstration projects such as the Oncology Care Model (OCM), health care professionals will lose incentive to use more expensive treatments. The Center for Medicare \& Medicaid Innovation has developed the OCM payment and delivery model to improve the effectiveness, efficiency, quality, and coordination of oncology care at the same or lower cost to Medicare.$^{58}$ In cases where the place of service, not baseline cost, drives profit, contracting between biopharmaceutical manufacturers and health care providers (such as through group purchasing organizations) could provide contracted discounts to large institutions. This practice would maintain provider margins when using lower-cost drugs such as biosimilars. Consolidation of health care provider services may result in a speedier and more efficient adoption of biosimilars because of greater consistency across formularies and reduced administrative burden.

Incentives may be required to encourage patients to switch to biosimilars, including passing on some of the expected savings due to lower drug acquisition costs through lower out-of-pocket costs. In order to address the Medicare Part D donut hole situation, where out-of-pocket costs can be higher with lower-cost biosimilars than with originator biologics, Avalere Health suggests either requiring manufacturer discounts for biosimilars when Part D beneficiaries are in the coverage gap or creating a formulary tier for biosimilars that would require reduced cost sharing compared with biologics in the traditional specialty tier. ${ }^{50,51}$

\section{Other factors affecting US health care reform}

Although biosimilar uptake may reduce health care costs while improving access and quality of care, other factors will also influence the future of health care reform in the USA, most notably ongoing policy discussions regarding the future of the ACA under the current administration. In the broadest sense, the economic environment may impact health care costs. ${ }^{13}$ In past economic slowdowns, spending on new and expensive technologies, particularly those with uncertain benefits, was scaled back..$^{14}$ These reductions occurred even before ACA cost initiatives changed perceptions and spending behavior by highlighting the importance of health care cost. ${ }^{3}$ Social factors such as disparities in income, education, and health literacy also have a considerable impact on health care utilization (eg, using the emergency department in lieu of primary care or foregoing preventive care) and outcomes, which in turn affect costs.

Kaiser Health News reports that hospital mergers, provider consolidation, and insufficient competition in the exchange market may drive up health care costs. ${ }^{59}$ Many hospitals are joining forces and purchasing physician practices as they gear up to become integrated systems, leaving fewer independent hospitals and doctors. ${ }^{59}$ With the greater market share gained by these health systems as they consolidate, their leverage in negotiations with insurers grows and may result in increased prices as well as limited patient choice. Insufficient competition exists between exchange plans due to mergers and tax breaks on employer-provided plans. ${ }^{14}$ The increase in deductibles and copays may also affect health care costs. ${ }^{14}$ Large out-of-pocket cost exposure and inadequate subsidies mean middle-class households face substantial and uncertain costs with exchange plans, as subsidies are focused on those with low income. ${ }^{16}$

Better solutions are required to address rising health care costs and future demand..$^{14,60}$ Negotiating drug prices and discounts is a good solution in theory, but more difficult in practice, and a universal "value" framework for drug reimbursement and adoption is still needed. ${ }^{14}$ There is a need for Medicare to increase value payments and optimize value utilization. ${ }^{3}$ For specialty drugs, stakeholders, including payers and providers, have implemented innovative strategies to ensure appropriate utilization and management; these will continue along with health care reform practices. ${ }^{60}$ However, drug spend is just one aspect of health care costs, ${ }^{14}$ and complementary strategies, including correctly identifying opportunities for containing other rising costs and value improvement, are required. ${ }^{3}$ 


\section{Conclusion}

The ACA has partly achieved some of its triple aims of increasing health coverage, reducing costs, and improving quality of care. However, the opportunity remains to change the way health care is administered to achieve fully the aims of health care reform. Although the future is uncertain, given administrative changes, the increased use of biosimilars in the US health care system could enable stakeholders to better achieve expanded access, reduce costs, and improve the quality of care.

\section{Acknowledgments}

Medical writing support was provided by Jennifer Priaulx and Karen Smoyer of Engage Scientific Solutions. This review was funded and sponsored by Pfizer Inc.

\section{Author contributions}

All authors contributed toward data analysis, drafting and revising the paper and agree to be accountable for all aspects of the work.

\section{Disclosure}

Ralph Boccia has received payment from Pfizer Inc. and from Sandoz to serve on advisory boards for their biosimilar platforms. Gilberto de Lima Lopes Jr reports personal fees from Pfizer Inc. and grants and personal fees from Fresenius Kabi and Sandoz. Ira Jacobs and Robert Popovian are employees and stockholders of Pfizer Inc. The authors report no other conflicts of interest in this work.

\section{References}

1. US Congress. The Patient Protection and Affordable Care Act. Washington, DC: US Department of Health \& Human Services, Healthcare. gov; 2010 [updated March 23, 2010]. Available from: https://www. healthcare.gov/glossary/patient-protection-and-affordable-care-act/. Accessed April 6, 2017.

2. Obama B. United States health care reform: progress to date and next steps. JAMA. 2016;316(5):525-532.

3. Orszag PR. US health care reform: cost containment and improvement in quality. JAMA. 2016;316(5):493-495.

4. US Congress. Key features of the Affordable Care Act by year. Baltimore, MD: US Department of Health \& Human Services; 2015 [updated November 18, 2014]. Available from: http://www.hhs.gov/healthcare/ facts-and-features/key-features-of-aca/. Accessed April 6, 2017.

5. US Congress. The Patient Protection and Affordable Care Act Biologics Price Competition and Innovation Act. Washington, DC: Responsible Reform for the Middle Class; 2009. Available from: https://www.dpc. senate.gov/healthreformbill/healthbill27.pdf. Accessed April 6, 2017.

6. US Food and Drug Administration. Labeling for biosimilar products. Guidance for industry: Draft guidance. Silver Spring, MD: US Department of Health \& Human Services, Food and Drug Administration, Center for Drug Evaluation and Research (CDER), Center for Biologics Evaluation and Research (CBER); 2016 [updated March 2016]. Available from: https://www.fda.gov/downloads/Drugs/GuidanceComplianceRegulatoryInformation/Guidances/UCM493439.pdf. Accessed April 6, 2017.
7. Center for Drug Evaluation and Research. List of licensed biological products with (1) reference product exclusivity and (2) biosimilarity or interchangeability evaluations to date. Silver Spring, MD: US Food and Drug Administration; 2016. Available from: http:// www.fda.gov/downloads/Drugs/DevelopmentApprovalProcess/ HowDrugsareDevelopedandApproved/ApprovalApplications/TherapeuticBiologicApplications/Biosimilars/UCM439049.pdf. Accessed April 6, 2017.

8. European Medicines Agency. European public assessment reports. London: European Medicines Agency; 2016 [updated October 6, 2016]. Available from: http://www.ema.europa.eu/ema/index.jsp?curl=pages \%2Fmedicines\%2Flanding\%2Fepar_search.jsp\&mid=WC0b01ac05 8001d124\&searchTab=searchByAuthType\&alreadyLoaded=true\&is NewQuery=true \&status $=$ Authorised $\&$ keyword=Enter+keywords \&s earchType $=$ name \&taxonomyPath $=\&$ treeNumber $=\&$ searchGenericTy pe=biosimilars\&genericsKeywordSearch=Submit. Accessed April 6, 2017.

9. Falit BP, Singh SC, Brennan TA. Biosimilar competition in the United States: statutory incentives, payers, and pharmacy benefit managers. Health Aff (Millwood). 2015;34(2):294-301.

10. Brougher JT. The Biosimilars Act: promoting or discouraging the development of generic biologics?: a tug-of-war between generic and innovator biologics seems to be where drug developers are headed. Biotechnol Healthc. 2010;7(4):22-23.

11. US Food and Drug Administration. Nonproprietary naming of biologic products. Guidance for industry. Silver Spring, MD: US Department of Health and Human Services, Food and Drug Administration, Center for Drug Evaluation and Research (CDER), Center for Biologics Evaluation and Research (CBER); 2017 [updated January 2017]. Available from: https://www.fda.gov/downloads/drugs/guidances/ucm459987. pdf. Accessed April 6, 2017.

12. IMS Institute for Healthcare Informatics. Delivering on the potential of biosimilar medicines. The role of functioning competitive markets. Parsippany, NJ: IMS Health; 2016. Available from: http://www.imshealth. com/files/web/IMSH\%20Institute/Healthcare\%20Briefs/Documents/ IMS_Institute_Biosimilar_Brief_March_2016.pdf. Accessed April 6, 2017.

13. Bauchner H. The Affordable Care Act and the future of US health care. JAMA. 2016;316(5):492-493.

14. Skinner J, Chandra A. The past and future of the Affordable Care Act. JAMA. 2016;316(5):497-499.

15. Yeung W, Burns H 3rd., Loiacono D. Are ACOs the answer to high-value healthcare? Am Health Drug Benefits. 2011;4(7):441-450.

16. Butler SM. The future of the Affordable Care Act. Reassessment and revision. JAMA. 2016;316(5):495-497.

17. Evans M. Dartmouth-Hitchcock exits Medicare's Pioneer ACO program. New York, NY: Modern Healthcare; 2015 [updated October 20, 2015]. Available from: http://www.modernhealthcare.com/article/20151020/ NEWS/151029984. Accessed April 6, 2017.

18. Tracer Z. UnitedHealth to exit Obamacare in 16 states to stem losses. New York, NY: Bloomberg; 2016 [updated April 16, 2016]. Available from: http://www.bloomberg.com/news/articles/2016-04-19/unitedhealth-profit-beats-estimates-fueled-by-tech-unit-optum. Accessed April 6, 2017.

19. Blackstone EA, Joseph PF. The economics of biosimilars. Am Health Drug Benefits. 2013;6(8):469-478.

20. IMS Institute for Healthcare Informatics. Shaping the biosimilars opportunity: a global perspective on the evolving biosimilars landscape. Parsippany, NJ: IMS Health; 2011. Available from: http://weinberggroup.com/pdfs/Shaping_the_biosimiliars_opportunity_A_global_perspective_on_the_evolving_biosimiliars_landscape.pdf. Accessed April 6, 2017.

21. Centers for Medicare \& Medicaid Services. Memorandum: Part D requirements for biosimilar follow-on biological products. Baltimore, MD: US Department of Health \& Human Services; 2015 [updated March 30, 2015]. Available from: http://www.amcp.org/WorkArea/ DownloadAsset.aspx?id=19358. Accessed April 6, 2017. 
22. Mulcahy AW, Predmore Z, Mattke S. The cost savings potential of biosimilar drugs in the United States. Santa Monica, CA: Rand Corporation; 2014. Available from: https://www.rand.org/content/dam/rand/pubs/ perspectives/PE100/PE127/RAND_PE127.pdf. Accessed April 6, 2017.

23. Kitamura M. Bullied in Norway, Merck sees sales of blockbuster dive. New York, NY: Bloomberg; 2015 [updated April 22, 2015]. Available from: http://www.bloomberg.com/news/articles/2015-04-22/merck-getsbullied-in-norway-with-remicade-price-war. Accessed April 6, 2017.

24. Stanton D. Biosimilar discounts and switching will wipe-out J\&J's Remicade in Norway, says regulator [news report]. Crawley, England: BioPharma-Reporter.com, William Reed Business Media; 2015 [updated October 16, 2015]. Available from: http://www.biopharmareporter.com/Markets-Regulations/Biosimilar-discounts-will-wipeout-Janssen-s-Remicade-sales-in-Norway. Accessed April 6, 2017.

25. Dorner T, Strand V, Cornes P, et al. The changing landscape of biosimilars in rheumatology. Ann Rheum Dis. 2016;75(6):974-982.

26. Farfan-Portet MI, Gerkens S, Lepage-Nefkens I, Vinck I, Hulstaert F. Are biosimilars the next tool to guarantee cost-containment for pharmaceutical expenditures? Eur J Health Econ. 2014;15(3):223-228.

27. Drummond $M$, Martin M. Biosimilar value generation or value destruction? A workshop demonstrating uptake to date and quantifying savings made. In: 19th Annual European Congress of the International Society for Pharmacoeconomics \& Outcomes Research (ISPOR); November 2, 2016; Vienna, Austria.

28. Whitfield E, Adler J, Gebremariam A, Davis M. Insurance among young adults with inflammatory bowel disease: changes under the Affordable Care Act Dependent Provision. J Pediatr Gastroenterol Nutr. Epub 2016 Aug 10.

29. Trotta F, Mayer F, Mecozzi A, Amato L, Addis A. Impact of guidance on the prescription patterns of G-CSFs for the prevention of febrile neutropenia following anticancer chemotherapy: a population-based utilization study in the Lazio Region. BioDrugs. 2017;31(2):117-124.

30. Sun D, Andayani TM, Altyar A, MacDonald K, Abraham I. Potential cost savings from chemotherapy-induced febrile neutropenia with biosimilar filgrastim and expanded access to targeted antineoplastic treatment across the European Union G5 countries: a simulation study. Clin Ther. 2015;37(4):842-857.

31. CVS Health. 2017 formulary management strategy and 2017 standard formulary list of removals and updates. Woonsocket, RI: CVS Caremark; 2016 [updated 2016]. Available from: http://investors.cvshealth. com/ /media/Files/C/CVS-IR-v3/documents/02-aug-2016/2017-standard-formulary-list-of-removals-and-updates.pdf. Accessed April 6, 2017.

32. Bonakdar Tehrani A, Cunningham PJ. Closing the Medicare doughnut hole: changes in prescription drug utilization and out-of-pocket spending among Medicare beneficiaries with Part D coverage after the Affordable Care Act. Med Care. 2017;55(1):43-49.

33. Centers for Medicare \& Medicaid Services. 2017 ASP drug pricing files April 2017 update. Baltimore, MD: US Department of Health \& Human Services, cms.gov; 2017 [updated March 20, 2017]. Available from: https://www.cms.gov/Medicare/Medicare-Fee-for-Service-PartB-Drugs/McrPartBDrugAvgSalesPrice/2017ASPFiles.html. Accessed April 6, 2017.

34. Centers for Medicare \& Medicaid Services. Questions and answers about biosimilar products. Baltimore, MD: MLN Matters; 2015. Available from: https://www.cms.gov/Outreach-and-Education/MedicareLearning-Network-MLN/MLNMattersArticles/Downloads/SE1509. pdf. Accessed April 6, 2017.

35. Balanescu A, Wiland P. Maximizing early treatment with biologics in patients with rheumatoid arthritis: the ultimate breakthrough in joints preservation. Rheumatol Int. 2013;33(6):1379-1386.

36. Kennedy J, Wood EG. Medication costs and adherence of treatment before and after the Affordable Care Act: 1999-2015. Am J Public Health. 2016;106(10):1804-1807.

37. Liang BA, Mackey T. Emerging patient safety issues under health care reform: follow-on biologics and immunogenicity. Ther Clin Risk Manag. 2011;7:489-493.
38. Dummit LA, Kahvecioglu D, Marrufo G, et al. Association between hospital participation in a Medicare bundled payment initiative and payments and quality outcomes for lower extremity joint replacement episodes. JAMA. 2016;316(12):1267-1278.

39. Dalzell MD. How will biologics fit into healthcare reform? With so many variables, it's hard to predict what kind of market will exist for biologics and other specialty drugs in 2014. Current trends may provide some insight. Biotechnol Healthc. 2011;8(4):6-10.

40. Olson K. ASBM labeling survey. Cary, NC: Industry Standard Research (ISR); 2015 [updated February 2015]. Available from: http://docs. house.gov/meetings/IF/IF14/20160204/104408/HHRG-114-IF1420160204-SD010.pdf. Accessed April 6, 2017.

41. BiosimilarsCME.org. Exploring the future of biological therapy and the role of biosimilars. White Paper. Old Lyme, CT: The France Foundation; 2015 [updated June 30, 2015]. Available from: http://www.biosimilarscme.org/content/Biosimilars_whitepaper.pdf. Accessed April 6, 2017.

42. Coalition of State Rheumatology Organizations (CSRO). CSRO releases Physician Biosimilars Survey results [press release]. Schaumburg, IL: CSRO; 2016 [updated May 26, 2016]. Available from: http://csro.info/ app/document/8382846;jsessionid=P5zJOo6TwPYoXVXzwSYawvyM. undefined. Accessed April 6, 2017.

43. Alliance for Safe Biologic Medicines (ASBM). New ASBM survey provides physicians' views on biosimilar labeling [news release]. Arlington, VA: SafeBiologics; 2015. Available from: https://safebiologics.org/2015/03/new-asbm-survey-provides-physicians-views-onbiosimilar-labeling/. Accessed April 6, 2017.

44. Hallersten A, Furst W, Mezzasalma R. Physicians prefer greater detail in the biosimilar label (SmPC). Results of a survey across seven European countries. Regul Toxicol Pharmacol. 2016;77:275-281.

45. Cohen H, Beydoun D, Chien D, et al. Awareness, knowledge, and perceptions of biosimilars among specialty physicians. Adv Ther. 2016;33(12):2160-2172.

46. Jain RH, Schleicher SM, Atoria CL, Bach PB. Part B payment for drugs in Medicare: Phase 1 of CMS' proposed pilot and its impact on oncology care: Memorial Sloan Kettering Cancer Center; 2016. Available from: http://drugpricinglab.org/wp-content/uploads/2016/04/Part-B-PaymentPhase-1-Report-042216.pdf. Accessed April 11, 2016.

47. Health Resources \& Services Administration. 340B Drug Pricing Program. Washington, DC: US Department of Health \& Human Services; 2017 [updated March 20, 2017]. Available from: https://www.hrsa.gov/ opa/. Accessed April 6, 2017.

48. Pyenson BS, Fitch KV, Pelizzari PM. Cost drivers of cancer care: a retrospective analysis of Medicare and commercially insured population claim data, 2004-2014. New York, NY: Milliman; 2016. Available from: http://www.milliman.com/insight/2016/Cost-drivers-of-cancercare-A-retrospective-analysis-of-Medicare-and-commercially-insuredpopulation-claim-data-2004-2014/. Accessed April 6, 2017.

49. Dickson V. CMS finalizes site-neutral payment rule. New York, NY: Modern Healthcare; 2016 [updated November 1, 2106]. Available from: http://www.modernhealthcare.com/article/20161101/NEWS/ 161109982. Accessed April 6, 2017.

50. Avalere Health. Patient out-of-pocket costs for biosimilars in Medicare Part D. Washington, DC: Avalere Health; 2016. Available from: http:// go.avalere.com/acton/attachment/12909/f-02c0/1/-///-//20160412_ Patient \%20OOP\%20for\%20Biosimilars\%20in\%20Part\%20D.pdf. Accessed April 6, 2017.

51. Kelly C. Biosimilars pricing in Medicare Part D needs legislative fix, Avalere says. New York, NY: Pink Sheet Daily; 2016. Available from: https://pink. pharmamedtechbi.com/PS079306/Biosimilars-Pricing-In-Medicare-PartD-Needs-Legislative-Fix-Avalere-Says. Accessed April 6, 2017.

52. Kopenski FR, Holcomb K. Understanding biosimilars and projecting the cost savings to employers: update. Seattle, WA: Milliman; 2015. Available from: http://www.milliman.com/insight/2015/Understandingbiosimilars-and-projecting-the-cost-savings-to-employers-Update/. Accessed April 6, 2017.

53. Banthia V. Biosimilar regulation: bringing the United States up to speed with other markets. Minn J Law Sci Technol. 2015;16(2):879-916. 
54. Felix AE, Gupta A, Cohen JP, Riggs K. Barriers to market uptake of biosimilars in the US. GaBi J. 2016;3(3):108-115.

55. Dunne SS, Dunne CP. What do people really think of generic medicines? A systematic review and critical appraisal of literature on stakeholder perceptions of generic drugs. BMC Med. 2015;29(13):173.

56. Babar ZUD, Scahill S. Interventions promoting the acceptance and uptake of generic medicines: a narrative review of the literature. Health Policy. 2014;117(3): 285-296.

57. IMS Institute for Healthcare Informatics. The role of generic medicines in sustaining healthcare systems: a European perspective. Parsippany, NJ: IMS Health; 2015. Available from: https://www.imshealth.com/files/ web/IMSH\%20Institute/Healthcare\%20Briefs/IIHI_Generics_Healthcare_Brief.pdf. Accessed April 7, 2017.
58. Centers for Medicare \& Medicaid Services. Oncology care model. Baltimore, MD: US Department of Health \& Human Services; 2016 [updated January 6, 2017]. Available from: https://innovation.cms.gov/ initiatives/oncology-care/. Accessed April 6, 2017.

59. Gold J. Accountable Care Organizations, explained. Menlo Park, CA: Kaiser Health News; 2015 [updated September 14, 2015]. Available from: http://khn.org/news/aco-accountable-care-organization-faq/. Accessed April 6, 2017.

60. Patel BN, Audet PR. A review of approaches for the management of specialty pharmaceuticals in the United States. Pharmacoeconomics. 2014;32(11):1105-1114.
Cancer Management and Research

\section{Publish your work in this journal}

Cancer Management and Research is an international, peer-reviewed open access journal focusing on cancer research and the optimal use of preventative and integrated treatment interventions to achieve improved outcomes, enhanced survival and quality of life for the cancer patient The manuscript management system is completely online and includes

\section{Dovepress}

a very quick and fair peer-review system, which is all easy to use. Visit $\mathrm{http}: / /$ www.dovepress.com/testimonials.php to read real quotes from published authors. 